\title{
Solving 0-1 integer programming problem based on DNA strand displacement reaction network
}

\author{
Zhen Tang ${ }^{1}$, Zhixiang Yin ${ }^{1,2, *}$, Luhui Wang ${ }^{3}$, Jianzhong Cui ${ }^{4}$, Jing Yang ${ }^{1}$, Risheng \\ Wang ${ }^{1}$ \\ ${ }^{1}$ School of Mathematics and Big Data, Anhui University of Science \& Technology, \\ Huainan 232001, Anhui, China \\ ${ }^{2}$ School of Mathematics, Physics and Statistics, Shanghai University of Engineering Science, Shanghai \\ 201620, China \\ ${ }^{3}$ College of Life Sciences, Shanxi Normal University, Xi'an, 710119, China \\ ${ }^{4}$ Department of Computer, Huainan Union University, Huainan 232001, Anhui, China \\ *Corresponding author: zxyin66@163.com
}

\section{Contents}

S1 The sequence designs

S1.1 Introduction to NUPACK

S1.2 The sequences of the initial DNA strands

S1.3 The free energy of the secondary structure of the initial DNA strands

$\mathrm{S} 1.4$ The gel electrophoresis image of verifying the threshold reaction module

S2 Visual DSD codes

$\mathrm{S} 2.1$ Introduction to Visual DSD

S2.2 The DSD codes

\section{S1 The sequence designs}

\section{S1.1 Introduction to NUPACK}

NUPACK is a growing software suite for the analysis and design of nucleic acid structures, devices, and systems serving the needs of researchers in the fields of nucleic acid nanotechnology, molecular programming, synthetic biology, and across the life sciences more broadly. NUPACK can be used to Calculation of the partition function and minimum free energy (MFE) secondary structure for unpseudoknotted complexes of arbitrary numbers of interacting RNA or DNA strands, Calculation of the equilibrium concentrations for arbitrary species of complexes in a dilute solution, and sequence design for one or more strands intended to adopt an unpseudoknotted target secondary structure at equilibrium. Most of this software may be conveniently run using the NUPACK web application at http://www.nupack.org (Zadeh, J. N., Steenberg, C. D., Bois, J. S., Wolfe, B. R., Pierce, M. B., Khan, A. R., Dirks, R. M., and Pierce, N. A. (2011) NUPACK: analysis and design of nucleic acid systems. $J$. Comput. Chem. 32, 170-173). 
S1.2 The sequences of the initial DNA strands

Supplementary Table 1 . The sequences of the initial DNA strands

\begin{tabular}{|c|c|c|}
\hline Component & Domains ( $\left.5^{\prime}-3^{\prime}\right)$ & Sequence (5'-3') \\
\hline ss-DNA X1 & $x_{1}-a-b-c$ & TCTC-ACC-ATT-CCCACG \\
\hline ss-DNA X2 & $x_{2}-a-b-c$ & TCCT-ACC-ATT-CCCACG \\
\hline ss-DNA X3 & $x_{3}-a-b-c$ & CTCT-ACC-ATT-CCCACG \\
\hline \multirow[t]{2}{*}{ Auxiliary complex M11 } & $\begin{array}{l}\text { M11-a: } \\
b-c-x_{1}-a-x_{1}-a-x_{1}-a-x_{1}-a\end{array}$ & $\begin{array}{l}\text { ATT-CCCACG-TCTC-ACC-T } \\
\text { CTC-ACC-TCTC-ACC- } \\
\text { TCTC-ACC }\end{array}$ \\
\hline & M11-b: $c^{*}-b^{*}-a^{*}$ & CGTGGG-AAT-GGT \\
\hline \multirow[b]{2}{*}{ Auxiliary complex N11 } & $\begin{array}{l}\text { N11-a: } \\
x_{1}-a-b-c, x_{1}-a-b-c \\
x_{1}-a-b-c, x_{1}-a-b-c\end{array}$ & $\begin{array}{l}\text { TCTC-ACC-ATT-CCCACG-T } \\
\text { CTC-ACC-ATT-CCCACG-T } \\
\text { CTC-ACC-ATT-CCCACG-T } \\
\text { CTC-ACC-ATT-CCCACG }\end{array}$ \\
\hline & $\begin{array}{l}\text { N11-b: } \\
a^{*}-x_{1}^{*}-a^{*}-x_{1}^{*}-a^{*}-x_{1}^{*} \\
-a^{*}-x_{1}^{*}-c^{*}\end{array}$ & $\begin{array}{l}\text { GGT-GAGA-GGT-GAGA-G } \\
\text { GT-GAGA-GGT-GAGA- } \\
\text { CGTGGG }\end{array}$ \\
\hline \multirow[t]{2}{*}{ Auxiliary complex M13 } & $\begin{array}{l}\text { M13-a: } \\
b-c-x_{3}-a-x_{3}-a-x_{3}-a\end{array}$ & $\begin{array}{l}\text { ATT-CCCACG-CTCT-ACC- } \\
\text { СТCT-ACC-CTCT-ACC }\end{array}$ \\
\hline & M13-b: $c^{*}-b^{*}-a^{*}$ & CGTGGG-AAT-GGT \\
\hline \multirow{2}{*}{ Auxiliary complex N13 } & $\begin{array}{l}\text { N13-a: } \\
x_{3}-a-b-c-x_{3}-a-b-c \\
-x_{3}-a-b-c\end{array}$ & $\begin{array}{l}\text { CTCT-ACC-ATT-CCCACG- } \\
\text { СTCT-ACC-ATT-CCCACG- } \\
\text { CTCT-ACC-ATT-CCCACG }\end{array}$ \\
\hline & $\begin{array}{l}\text { N13-b: } \\
a^{*}-x_{3}^{*}-a^{*}-x_{3}^{*}-a^{*}-x_{3}^{*}-c^{*}\end{array}$ & $\begin{array}{l}\text { GGT-AGAG-GGT-AGAG-G } \\
\text { GT-AGAG-CGTGGG }\end{array}$ \\
\hline \multirow[b]{2}{*}{ Auxiliary complex G1 } & G1-a: $a-b-c$ & ACC-ATT-CCCACG \\
\hline & $\mathrm{G} 1-\mathrm{b}: c^{*}-b^{*}-a^{*}-x_{1}^{*}$ & CGTGGG-AAT-GGT-GAGA \\
\hline \multirow[b]{2}{*}{ Auxiliary complex G2 } & G2-a: $a-b-c$ & ACC-ATT-CCCACG \\
\hline & $\mathrm{G} 2-\mathrm{b}: c^{*}-b^{*}-a^{*}-x_{2}^{*}$ & CGTGGG-AAT-GGT-AGGA \\
\hline \multirow[b]{2}{*}{ Auxiliary complex G3 } & G3-a: $a-b-c$ & ACC-ATT-CCCACG \\
\hline & G3-b: $c^{*}-b^{*}-a^{*}-x_{3}^{*}$ & CGTGGG-AAT-GGT-AGAG \\
\hline \multirow{2}{*}{ Auxiliary complex P } & P-a: $c$ & CCCACG \\
\hline & P-b: $c^{*}-b^{*}-a^{*}$ & CGTGGG-AAT-GGT \\
\hline \multirow{2}{*}{ Auxiliary complex T } & T-a: $c-F A M$ & CCCACG -/56FAM/ \\
\hline & T-b: $F Q-c^{*}-b^{*}$ & /3IABkFQ/-CGTGGG-AAT \\
\hline
\end{tabular}


S1.3 The free energy of the secondary structure of the initial DNA strands

Supplementary Figure S1. The free energy of ss-DNA X1.

a b c

Supplementary Figure S2. The free energy of the secondary structure of ss-DNA X2. a b

Supplementary Figure S3. The free energy of of ss-DNA X3. 
Supplementary Figure S4. The free energy of auxiliary complex P.

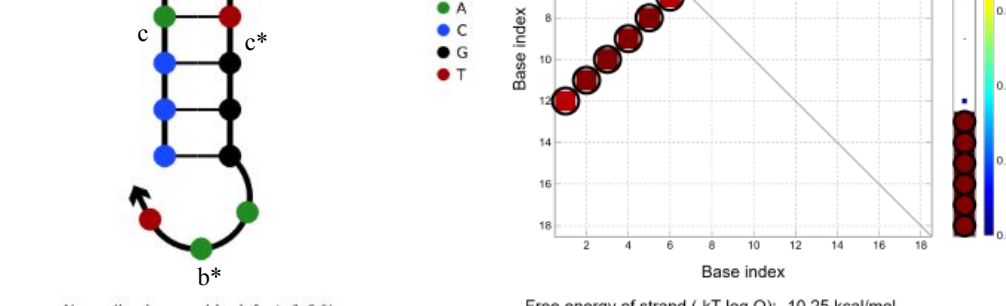

Supplementary Figure S5. The free energy of auxiliary complex T.

\section{S1.4 The gel electrophoresis image of verifying the threshold reaction module}

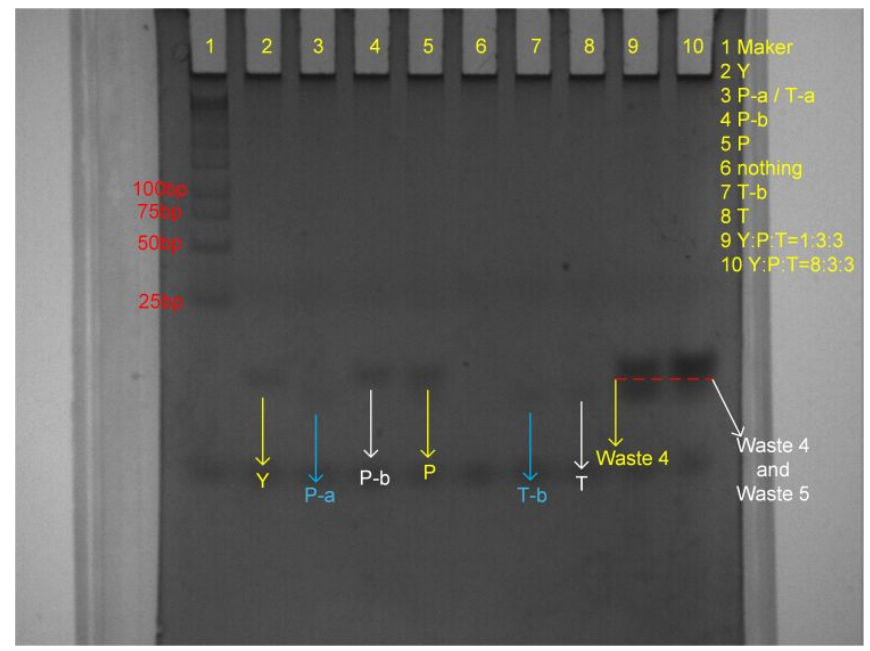

Supplementary Figure S6. The gel electrophoresis image of verifying the threshold reaction module. Taking the solutions $2(0,1,0)$ and $7(4,1,3)$ as example, we use gel electrophoresis to verify the threshold reaction module. Lanes 2, 3, 4 and 7 of the gel electrophoresis image show that there are only ss-DNA Y (12 nt), P-a (6 nt), P-b (12 nt) and T-b (9 nt) in the solution, respectively. Lanes 5 and 8 of the gel electrophoresis image show that there are only complexes $\mathrm{P}$ and $\mathrm{T}$ in the solution respectively. In lane 9, the reaction is based on the relative concentrations $\mathrm{Y}: \mathrm{P}: \mathrm{T}=1: 3: 3$ (the corresponding solution $2(0,1,0)$ ), only complex Waste4 is produced. The concentration of $\mathrm{Y}$ is less than that of complex $\mathrm{P}$, and $\mathrm{Y}$ preferentially reacts with complex $\mathrm{P}$. In lane 10, the reaction is based on the relative concentrations Y: P: $\mathrm{T}=8: 3: 3$ (the corresponding solution 7(4, 1, 3)), complexes Waste4 and Waste5 are produced. The concentration of $\mathrm{Y}$ is higher than that of complex $\mathrm{P}$, and $\mathrm{Y}$ preferentially reacts with complex $\mathrm{P}$, and the remaining Y reacts with complex T. Due to their close base numbers, complex $\mathrm{P}$ and complex $\mathrm{T}$ are almost mixed together on the gel electrophoresis band. Band Waste4 and Waste 5 of lane 10 is obviously darker than lane 9. Taken together, the threshold reaction module is feasible. 


\section{S2 Visual DSD codes}

\section{S2.1 Introduction to Visual DSD}

Visual DSD is a simulation software with statistics, simulation, and visual display. It was originally proposed by Andrew Phillips and coworkers in 2009 (Phillips, A., and Cardelli, L. (2009) A programming language for composable DNA circuits. J. R. Soc., Interface 6, S419-S436.). Visual DSD can automatically demonstrate all possible displacement reactions between all kinds of DNA without the need to manually construct a reaction network. The user can visualize and analyze the design based on the results of the simulated reactions to eliminate any unnecessary reactions. Especially before doing biochemical experiments, the simulation results can effectively avoid the DNA types and wrong reactions required in model design, provide model efficiency, and reduce unnecessary losses in experiments. The downloadable versions are also available from https://dsd.azurewebsites.net/server, https://classicdsd.azurewebsites.net/, or https://dsd.azurewebsites.net/beta/2015 0325/. The version used in this paper is 'v2015-0325'.

\section{S2.2 The DSD codes}

For the first constraint equation of the 0-1 integer programming problem, the DSD code of $4 x_{1}$ (Fig. 6):

directive sample 10000.08000

directive simulation deterministicstiff

directive polymers

$\operatorname{def} \mathrm{X} 1()=<\mathrm{x} 1^{\wedge} \mathrm{a}^{\wedge} \mathrm{b}^{\wedge} \mathrm{c}^{\wedge}>$

$\operatorname{def} \mathrm{M} 11()=\left\{\mathrm{a}^{\wedge *}\right\}\left[\mathrm{b}^{\wedge} \mathrm{c}^{\wedge}\right]<\mathrm{x} 1^{\wedge} \mathrm{a}^{\wedge} \mathrm{x} 1^{\wedge} \mathrm{a}^{\wedge} \mathrm{x} 1^{\wedge} \mathrm{a}^{\wedge} \mathrm{x} 1^{\wedge} \mathrm{a}^{\wedge}>$

$\operatorname{def} \mathrm{N} 11()=\left\{\mathrm{c}^{\wedge *}\right\}\left[\mathrm{x} 1^{\wedge} \mathrm{a}^{\wedge}\right]<\mathrm{b}^{\wedge} \mathrm{c}^{\wedge}>:\left[\mathrm{x} 1^{\wedge} \mathrm{a}^{\wedge}\right]<\mathrm{b}^{\wedge} \mathrm{c}^{\wedge}>:\left[\mathrm{x} 1^{\wedge} \mathrm{a}^{\wedge}\right]<\mathrm{b}^{\wedge} \mathrm{c}^{\wedge}>:\left[\mathrm{x} 1^{\wedge} \mathrm{a}^{\wedge}\right]<\mathrm{b}^{\wedge} \mathrm{c}^{\wedge}>$

$(1 * \mathrm{X} 1)$

| $1 * \mathrm{M} 11()$

| $6 * \mathrm{~N} 11()$

)

For the first constraint equation of the 0-1 integer programming problem, the DSD code of $3 x_{3}$

(Fig. 8):

directive sample 10000.08000

directive simulation deterministicstiff

directive polymers

$\operatorname{def} \mathrm{X} 3()=<\mathrm{x} 3^{\wedge} \mathrm{a}^{\wedge} \mathrm{b}^{\wedge} \mathrm{c}^{\wedge}>$

$\operatorname{def} \mathrm{M} 13()=\left\{\mathrm{a}^{\wedge}\right\}\left[\mathrm{b}^{\wedge} \mathrm{c}^{\wedge}\right]<\mathrm{x} 3^{\wedge} \mathrm{a}^{\wedge} \mathrm{x} 3^{\wedge} \mathrm{a}^{\wedge} \mathrm{x} 3^{\wedge} \mathrm{a}^{\wedge}>$

$\operatorname{def} \mathrm{N} 13()=\left\{\mathrm{c}^{\wedge *}\right\}\left[\mathrm{x} 3^{\wedge} \mathrm{a}^{\wedge}\right]<\mathrm{b}^{\wedge} \mathrm{c}^{\wedge}>:\left[\mathrm{x} 3^{\wedge} \mathrm{a}^{\wedge}\right]<\mathrm{b}^{\wedge} \mathrm{c}^{\wedge}>:\left[\mathrm{x} 3^{\wedge} \mathrm{a}^{\wedge}\right]<\mathrm{b}^{\wedge} \mathrm{c}^{\wedge}>$

$(1 * \mathrm{X} 3()$

| $1 * \mathrm{M} 13()$

| $5 * \mathrm{~N} 13($ )

)

For the first constraint equation of the 0-1 integer programming problem, the DSD code of sum reaction module of the $4 x_{1}, x_{2}, 3 x_{3}$ (Fig. 10):

directive sample 6000.01000

directive simulation deterministicstiff 


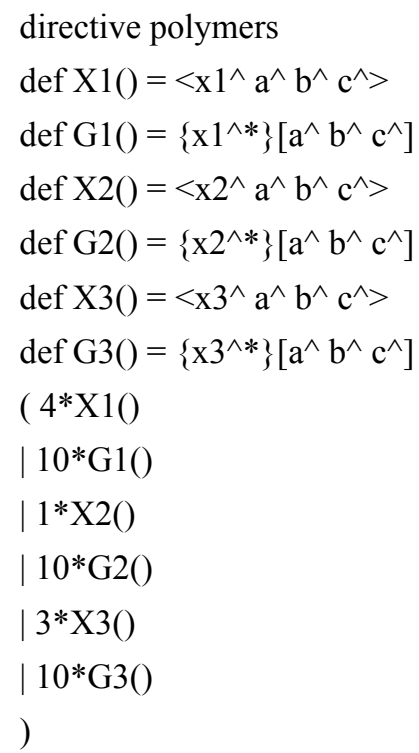

For the first constraint equation of the 0-1 integer programming problem, the DSD code of threshold reaction module of the third solution. (Fig. 11a):

directive simulation \{

final $=50$;

\}

directive parameters $[\mathrm{k}=0.003 ; \mathrm{u}=0.1]$

directive compilation infinite

dom $\mathrm{a}=\{$ bind $=\mathrm{k}$; unbind $=\mathrm{u}\}$

dom $\mathrm{b}=\{$ bind $=\mathrm{k}$; unbind $=\mathrm{u}\}$

$\operatorname{dom} \mathrm{F}=\{$ bind $=\mathrm{k}$; unbind $=\mathrm{u}\}$

$\operatorname{dom} \mathrm{Q}=\{$ bind $=\mathrm{k}$; unbind $=\mathrm{u}\}$

dom $1 \mathrm{~h}=\left\{\right.$ bind $=5^{*} \mathrm{k}$; unbind $=\mathrm{u}$; subdomains $\left.=[\mathrm{a} ; \mathrm{b}]\right\}$

$\operatorname{def} \mathrm{Y}()=\left\{\mathrm{a}^{\wedge} \mathrm{b}^{\wedge} \mathrm{c} 1^{\wedge} \mathrm{c} 2^{\wedge}\right\}$

$\operatorname{def} \mathrm{P}()=<\mathrm{a}^{\wedge *} \mathrm{~b}^{\wedge *}>\left[\mathrm{c} 1^{\wedge *} \mathrm{c} 2^{\wedge *} \mathrm{Q}^{\wedge *}\right]$

$\operatorname{def} \mathrm{T}()=\left\langle\mathrm{b}^{\wedge *}>\left[\mathrm{c} 1^{\wedge *} \mathrm{c} 2^{\wedge *}\right]\right.$

$(1 * \mathrm{Y}()$

|3*P()

|3*T()

)

For the first constraint equation of the 0-1 integer programming problem, the DSD code of threshold reaction module of the eighth solution. (Fig. 11b):

directive simulation \{

$$
\text { final }=50 \text {; }
$$

\}

directive parameters $[\mathrm{k}=0.003 ; \mathrm{u}=0.1]$

directive compilation infinite

dom $\mathrm{a}=\{$ bind $=\mathrm{k}$; unbind $=\mathrm{u}\}$

$\operatorname{dom} \mathrm{b}=\{$ bind $=\mathrm{k}$; unbind $=\mathrm{u}\}$

$\operatorname{dom} \mathrm{F}=\{$ bind $=\mathrm{k}$; unbind $=\mathrm{u}\}$ 


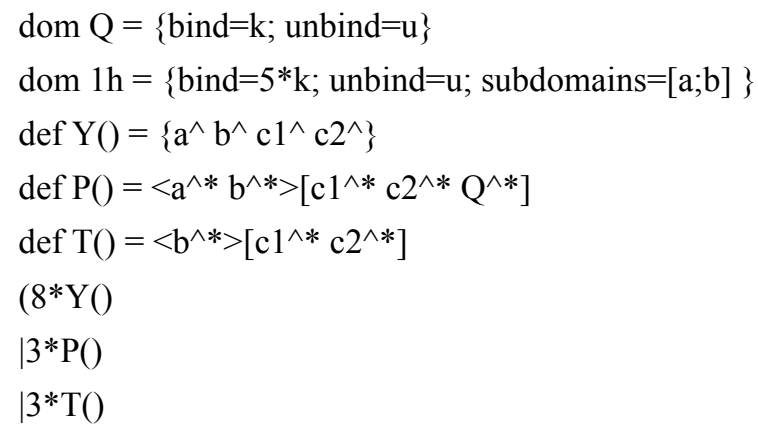

For the second constraint equation of the 0-1 integer programming problem, the DSD code of threshold reaction module of the fourth solution. (Fig. 12a):

directive simulation \{

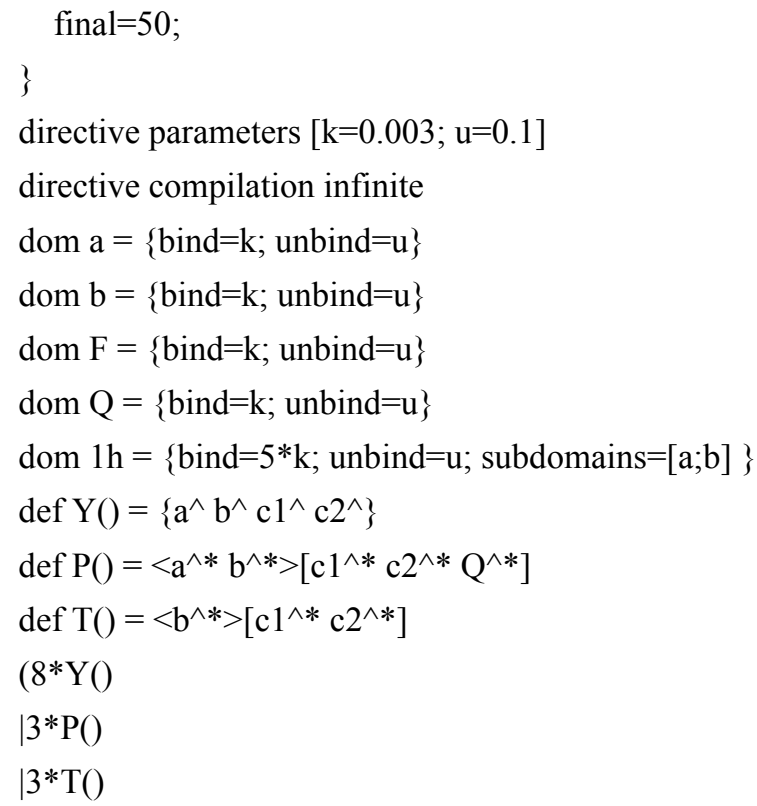

For the second constraint equation of the 0-1 integer programming problem, the DSD code of threshold reaction module of the fifth solution. (Fig. 12b):

directive simulation \{

final $=50$;

\}

directive parameters $[\mathrm{k}=0.003 ; \mathrm{u}=0.1]$

directive compilation infinite

dom $\mathrm{a}=\{$ bind $=\mathrm{k}$; unbind $=\mathrm{u}\}$

$\operatorname{dom} \mathrm{b}=\{$ bind $=\mathrm{k}$; unbind $=\mathrm{u}\}$

$\operatorname{dom} \mathrm{F}=\{$ bind $=\mathrm{k}$; unbind $=\mathrm{u}\}$

$\operatorname{dom} \mathrm{Q}=\{$ bind $=\mathrm{k}$; unbind $=\mathrm{u}\}$

$\operatorname{dom} 1 \mathrm{~h}=\left\{\right.$ bind $=5^{*} \mathrm{k}$; unbind $=\mathrm{u}$; subdomains $\left.=[\mathrm{a} ; \mathrm{b}]\right\}$

$\operatorname{def} \mathrm{Y}()=\left\{\mathrm{a}^{\wedge} \mathrm{b}^{\wedge} \mathrm{c} 1^{\wedge} \mathrm{c} 2^{\wedge}\right\}$

$\operatorname{def} \mathrm{P}()=<\mathrm{a}^{\wedge *} \mathrm{~b}^{\wedge *}>\left[\mathrm{c} 1^{\wedge *} \mathrm{c} 2^{\wedge *} \mathrm{Q}^{\wedge *}\right]$

$\operatorname{def} \mathrm{T}()=\left\langle\mathrm{b}^{\wedge *}>\left[\mathrm{c} 1^{\wedge *} \mathrm{c} 2^{\wedge *}\right]\right.$ 
$(2 * \mathrm{Y}()$

|3*P()

|3* $\mathrm{T}()$

)

For the third constraint equation of the 0-1 integer programming problem, the DSD code of threshold reaction module of the seventh solution. (Fig. 13):

directive simulation \{

$$
\text { final }=50 \text {; }
$$

\}

directive parameters $[\mathrm{k}=0.003 ; \mathrm{u}=0.1]$

directive compilation infinite

dom $\mathrm{a}=\{$ bind $=\mathrm{k}$; unbind $=\mathrm{u}\}$

$\operatorname{dom} \mathrm{b}=\{$ bind $=\mathrm{k} ;$ unbind $=\mathrm{u}\}$

$\operatorname{dom} \mathrm{F}=\{$ bind $=\mathrm{k} ;$ unbind $=\mathrm{u}\}$

$\operatorname{dom} \mathrm{Q}=\{$ bind $=\mathrm{k} ;$ unbind $=\mathrm{u}\}$

$\operatorname{dom} 1 \mathrm{~h}=\left\{\right.$ bind $=5^{*} \mathrm{k}$; unbind $=\mathrm{u}$; subdomains $\left.=[\mathrm{a} ; \mathrm{b}]\right\}$

$\operatorname{def} \mathrm{Y}()=\left\{\mathrm{a}^{\wedge} \mathrm{b}^{\wedge} \mathrm{c} 1^{\wedge} \mathrm{c} 2^{\wedge}\right\}$

$\operatorname{def} \mathrm{P}()=<\mathrm{a}^{\wedge *} \mathrm{~b}^{\wedge *}>\left[\mathrm{c} 1^{\wedge *} \mathrm{c} 2^{\wedge *} \mathrm{Q}^{\wedge *}\right]$

$\operatorname{def} \mathrm{T}()=<\mathrm{b}^{\wedge *>}\left[\mathrm{c} 1^{\wedge *} \mathrm{c} 2^{\wedge *}\right]$

$(2 * \mathrm{Y}()$

|3* $\mathrm{P}()$

|3*T()

) 